\title{
Neural Network based Electrostatic Fields Distribution Modeling for Harmattan Season in Zaria, Nigeria
}

\author{
Akinsanmi O. \\ Dept. of Electrical and Computer Engineering, \\ Ahmadu Bello University \\ Zaria, Nigeria
}

\author{
Ekundayo K. R. \\ Dept. of Electrical and Computer Engineering, \\ Ahmadu Bello University \\ Zaria, Nigeria
}

\begin{abstract}
This paper presents the application of neural network to the electrostatic field distribution modeling using harmattan season data in Zaria, Nigeria. The data was captured through an on-line mechanism for twenty-four months by the computer using the Microsoft Office Excel Program for twenty-four months (February, 2007 - February, 2009). The focus of the analysis is determining the effect of environmental factors such as temperature, pressure and relative humidity on the static electric field during the harmattan season. The plots of the electrostatic field against the variation of the environmental factors were used as the qualitative analytical tools and yielded a non-linear relationship. The data was analyzed using Neural Network version 3.24 Software, to establish predictive models for Harmattan outside and inside Scenarios. The result of the analyses yielded good neural statistical values of Root Mean Square Error (RMSE) of 0.09, and Pearson R value of 0.76 for outside Scenario. Similarly for Harmattan inside Scenario, gives a RMSE value of 0.14 , and Pearson $R$ value of 0.77 respectively, which are reflections of a good model. The result was further buttressed by the plot of the Neural Network based Electrostatic Fields distribution modeling of the experimental and the predicted parameters. With the insignificant values of the RMSE, Pearson $\mathrm{R}$ value which are reflections of the closeness of the predicted and the experimental parameters, hence the could be relied upon to predict the electrostatic fields during harmattan in Zaria, Nigeria.
\end{abstract}

\section{General Terms}

The submitted material is classifications under Artificial Neural Network and Computational Electromagnetics.

\section{Keywords}

Electrostatic field, Neural network, Electrostatic fields Distribution models, environmental factors

\section{INTRODUCTION}

The neural networks are natural complementary tools in building intelligent systems that combines with a EUROfuzzy logic intelligent system network [2]. Neural network is an aspect of neuro-fuzzy logic that is used to carry mathematical modeling of physical phenomenon by handling complex input and output relationships [1]. Neural network are good at recognizing patterns, they are not good at explaining how they reach their decisions. While Fuzzy logic systems, which can reason with imprecise information, are good at explaining their decisions (restricted domain applications) but they cannot automatically acquire the rules they use to make those decisions [3][4]. From a mathematical point of view, Neural Net is a complex nonlinear function with many parameters that can be adjusted (calibrated or trained) in such a way that the output becomes similar to the measured output on a known data [5].

This means that the Neural Net is able to generalize relevant output for a set of previously unseen input data [6]. In essence, it can be considered as universal approximations of non-linear dependencies trained by experimental data [7]. Neural Nets can, therefore, be trained to approximate any continuous function to any desired accuracy, without a need to specify its type. They can also be applied to incomplete or corrupted data and still yield acceptable results because the Neural Nets are relatively fault-tolerant having many processing nodes [8][9][10]. The proficiency of Multilayer Perceptron as a suitable model for atmospheric prediction has been established [11]. The usefulness of Artificial Neural Network in atmospheric modeling and its potential over conventional weather prediction model has also been proved [12][13].

Zaria is located within the co-ordinate position of latitude $11^{0} \mathrm{~N}$ and Longitude $8^{0} \mathrm{E}$ above sea level. This falls within the Sahara zone, where harmattan activities exist due to the operation of the North- East trade wind. Harmattan is a natural phenomenon which describe the very dry dust - laden atmosphere, which rises in the Sahara desert and is carried south by winds from that area within the West-Africa region periodically from October - March of every year. This is common to the dry season of the Savannah region [14].

\section{MATERIAL AND METHODS}

Neural Network Predict module is an essential element of the model topology which requires specification and configuration of the network parameters. The maximum number of iteration of 250 was used because it shows a better trend between the actual and the predicted field when compared with the other numbers of iterations. Data Transformation is used to convert data into a form suitable for building effective models. The data was optimized using Comprehensive Data Transformation because it generates a richer set of transforms than the moderate mode. Comprehensive Transformation gives better results but takes more computing time, but with computer systems this is easily achieved [15]. Optimization is achieved by adjusting the neural network model parameters to give the best model. The Model Building Wizard (Figure 1) guides the building of a new model based on information provided by the user, such as 
the location, structure and characteristics of the data, and the architecture of the model. This is done in a number of steps as shown in figures 2 to 9 .

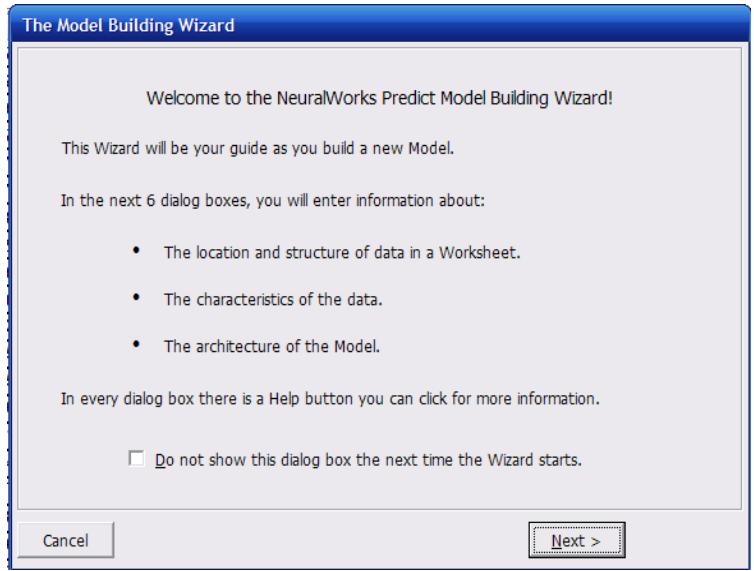

Figure 1: The Model Building Wizard

1. The name of model is inputted and the row containing the names of its data fields is specified as shown in Figure 2

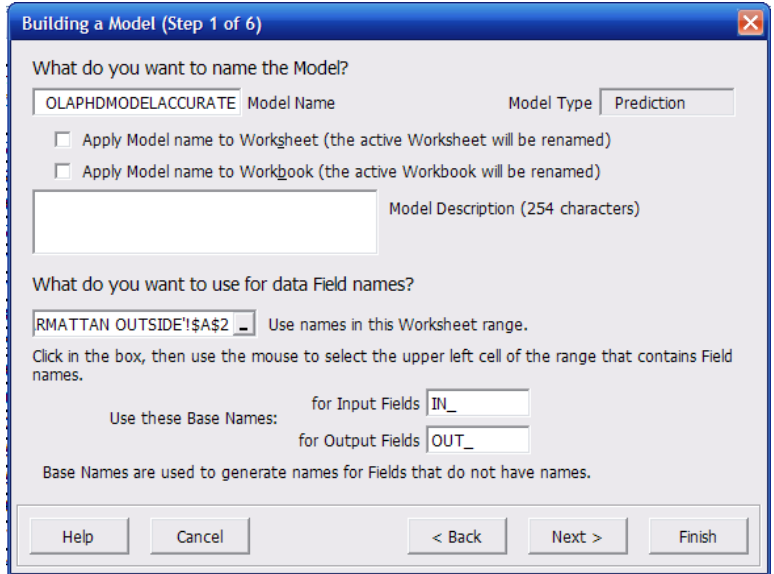

Figure 2: Specifying the Model Name

2. The location of input fields is specified input cells in the first data record, and range of cells that represent all input data as shown in Figure 3.

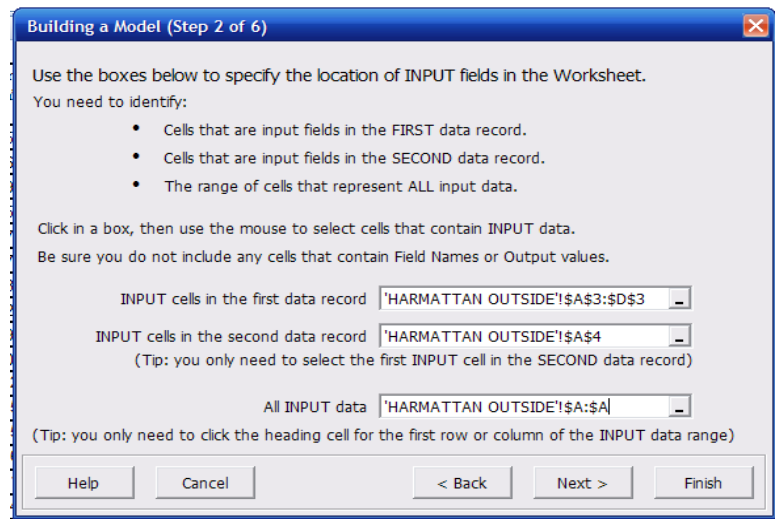

Figure 3: Specifying Input Fields
3. The location of target output cells are specified, as seen in Figure 4:

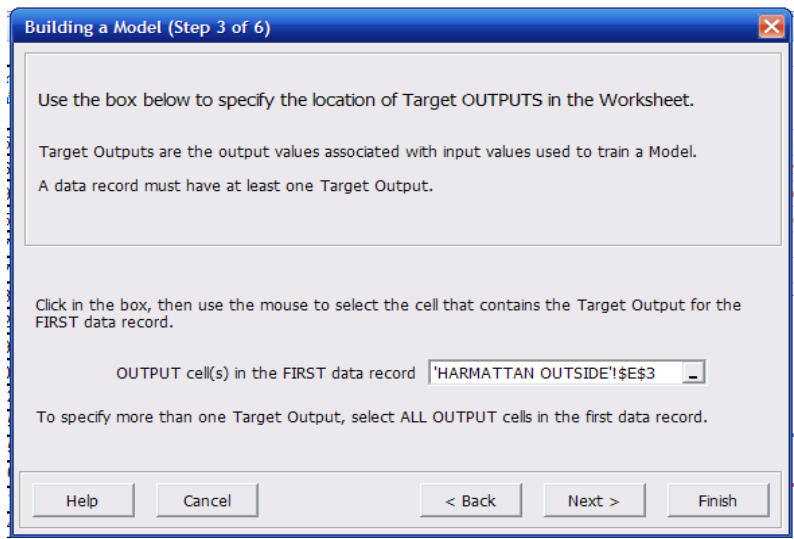

Fig. 4: Specifying location of Outputs

4. The level of noise (variability) in the data which influences how the program avoids over fitting is achieved in Figure 5.

\begin{tabular}{|l|}
\hline Building a Model (Step 4 of 6 ) \\
How much variability, or "noise" is in the data? \\
The amount of noise influences how Predict avoids over-fitting. \\
Select a noise level from the list below: \\
moderately noisy data \\
"Moderately noisy data" is a good choice for most kinds of data. \\
How thoroughly should Predict explore transformations of data? \\
Predict analyzes and transforms data to find good distributions of values to use as candidates \\
for Model input. \\
Select a data transformation level from the list below: \\
comprehensive data transformation \\
"Moderate data transformation" is a good choice for most Models. \\
Help Cancel
\end{tabular}

\section{Figure 5: Determination of Noise and Data} Transformation Levels

5. At this stage, it is stated how input fields should be analysed and the Neural Network built as shown in Figure 6 .

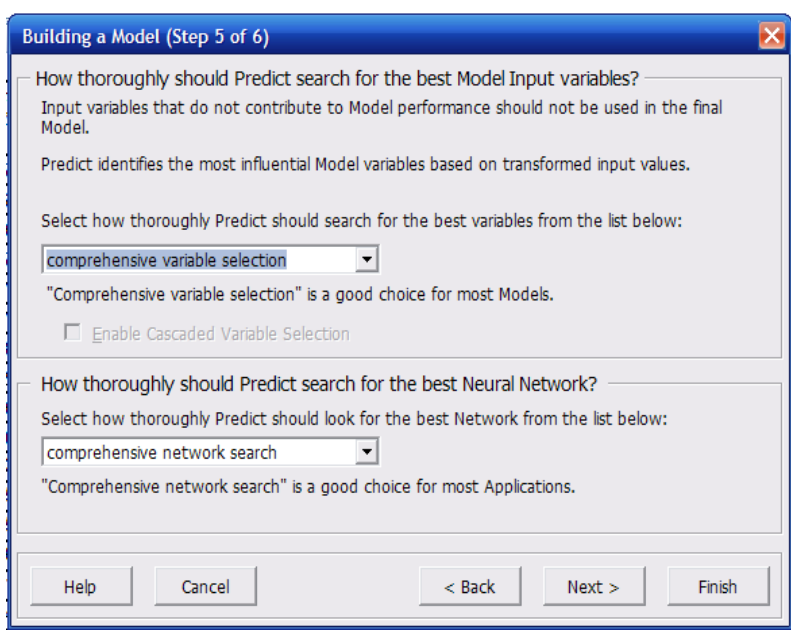

Figure 6: Building a Model 
6. All the model parameter settings of the previous steps are displayed as shown in Figure 7. After verifying their accuracy, the model is then trained.

\begin{tabular}{|c|c|c|c|c|}
\hline \multirow{2}{*}{\multicolumn{5}{|c|}{$\begin{array}{l}\text { Building a Model (Step } 6 \text { of } 6 \text { ) } \\
\text { Please review Model parameter settings before you click Train }\end{array}$}} \\
\hline & & & & \\
\hline OLAPHDMODELACCURATE Model Name & & Model Type | Predict & tion & \\
\hline \multicolumn{5}{|l|}{$\ulcorner$ Apply Model name to Worksheet } \\
\hline \multicolumn{5}{|l|}{$\Gamma$ Apply Model name to Workbook } \\
\hline Field Names $\longdiv { A 2 }$ & Base Names & In $\sqrt{\mathbb{I N}}$ & out ou & \\
\hline First Input Record $\overline{A 3: D 3}$ & \multicolumn{4}{|c|}{ moderately noisy data } \\
\hline Second Input Record $A 4: D 4$ & \multicolumn{4}{|c|}{ comprehensive data transformation } \\
\hline All Input Data $\mid$ A3:D142 & \multicolumn{4}{|c|}{ comprehensive variable selection } \\
\hline First Target Output(s) E3 & \multicolumn{4}{|c|}{$\ulcorner$ Enable Cascaded Variable Selection } \\
\hline $\begin{array}{llll}\text { All Target Output(s) } & \text { E3:E142 }\end{array}$ & \multicolumn{4}{|c|}{ comprehensive network search } \\
\hline \multicolumn{5}{|l|}{$\Gamma$ Include Sheet Name with Excel ranges } \\
\hline$\Gamma$ Include Workbook Name with Excel ranges & \multicolumn{4}{|c|}{ More Parameters... } \\
\hline \multicolumn{5}{|l|}{$\Gamma$ Write Log File } \\
\hline Cancel & $<$ Back & Save As... & Tra & \\
\hline
\end{tabular}

Figure 7: Review Model Parameter Settings

7. The Training Complete dialog box is displayed showing the summary statistics about the model and its performance on modeling data. The basic statistics related to the performance of the train data used to measure the quality of the model are obtained by means of the Test command as shown in Figure 8.

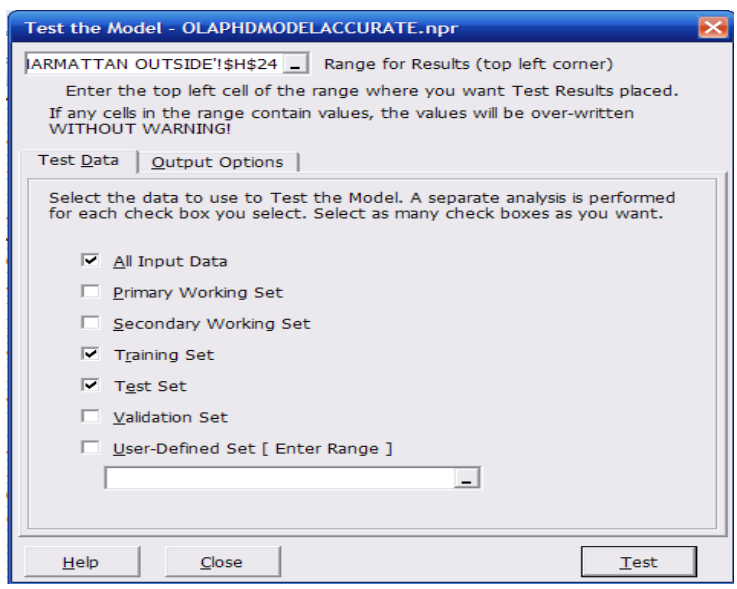

Figure 8: Testing the Model

8. A total of 140 input data for the Harmattan season were used. The model was then run as shown in Figure 9.

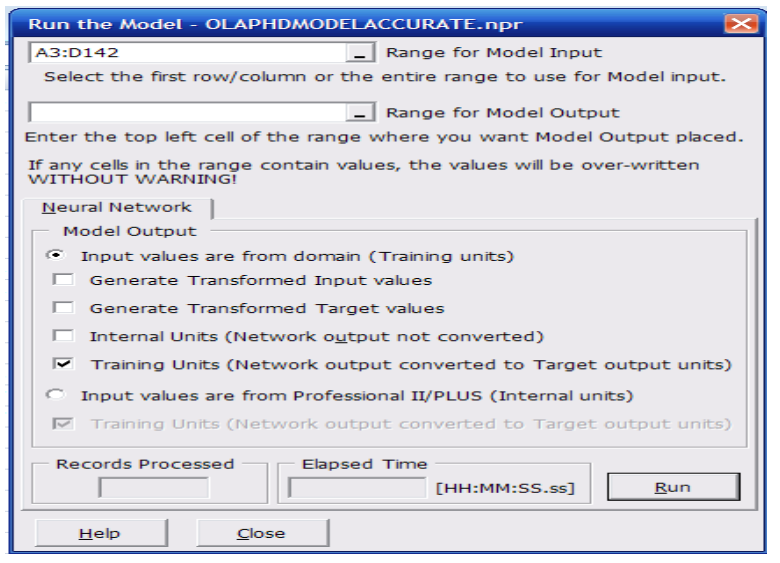

Figure 9: Running the Model

\section{RESULTS AND DISCUSSION}

The measurement was done between February 2007 and February 2009 in and outside the Thermodynamic Laboratory of the Department of Mechanical Engineering, Ahmadu Bello University, Zaria, Nigeria. Some of the results of the experimental measurements of electrostatic field are shown in Table 1. The co-related climatic parameters to harmattan such as temperature, pressure and relative humidity were also measured and analyzed relative to the measured electric field in Zaria. The validation of the results was achieved using the Neural Network Predicts Software using for the Harnattan (inside and outside) scenarios repectively are shown in Tables 1 and 2 .

The Neural Network Predict used to validate based on the Root Mean Square Error (RMSE) and the Pearson Correlation factor R. The R is a measure of how well the model follows the trends of the experimental data, while the RMSE is a function of the variation between the experimental data and the predicted one. The scenario was established for the Harmattan period in study area (Zaria), Nigeria. For the Neural Networks Predict model to be acceptable, the RMSE value must be close to zero while the Pearson Correlation factor $\mathrm{R}$ is a function of the problem domain. In this case must be greater than 0.5 for an acceptable model. The confidence level used in this case is $95 \%$. From Tables 1 to 2 , it could be observed that the operations of the models which are within the limits of the R-value (Pearson Correlation Factor) and the RMSE (root mean square error) value showed a percentage deviation from the experimental values of less than fifteen percent. In addition,the results of the Neural Network Predict analysis from Table 1 to 2 yielded the model plot of the Electrostatic Field during Harmattan seasons (inside and outside scenario) in Figure 10 and Figure 12, and the summary of Table 3 where the red colour indicate the Neural Network predicts while blue colour for experimental data as shown below:

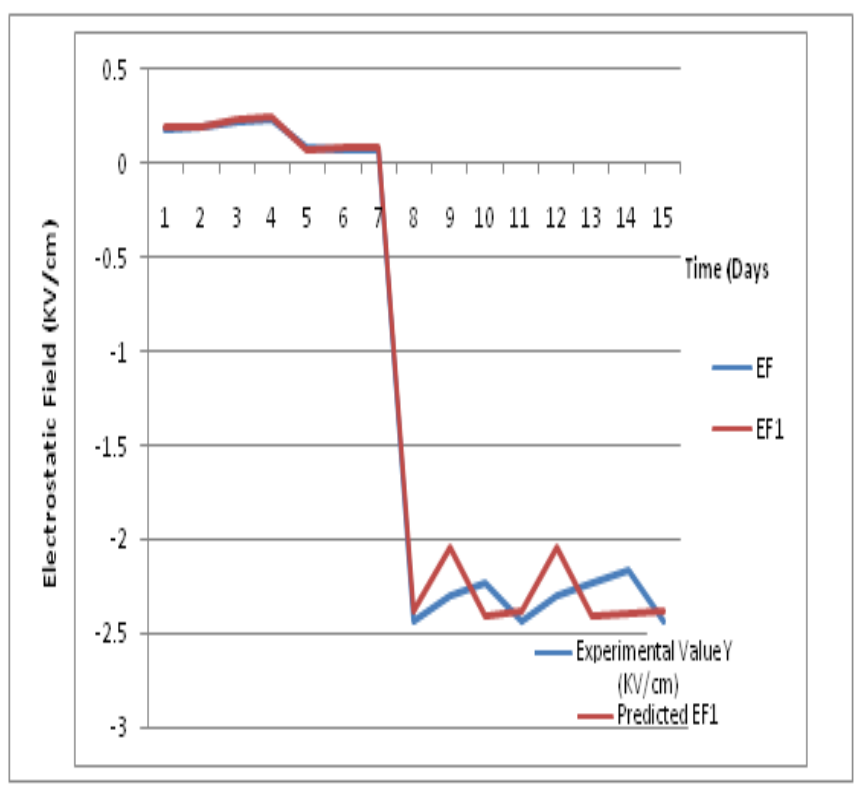

Figure 10: Model Plot of Electrostatic Field for Harmattan Season (Inside Scenario) 


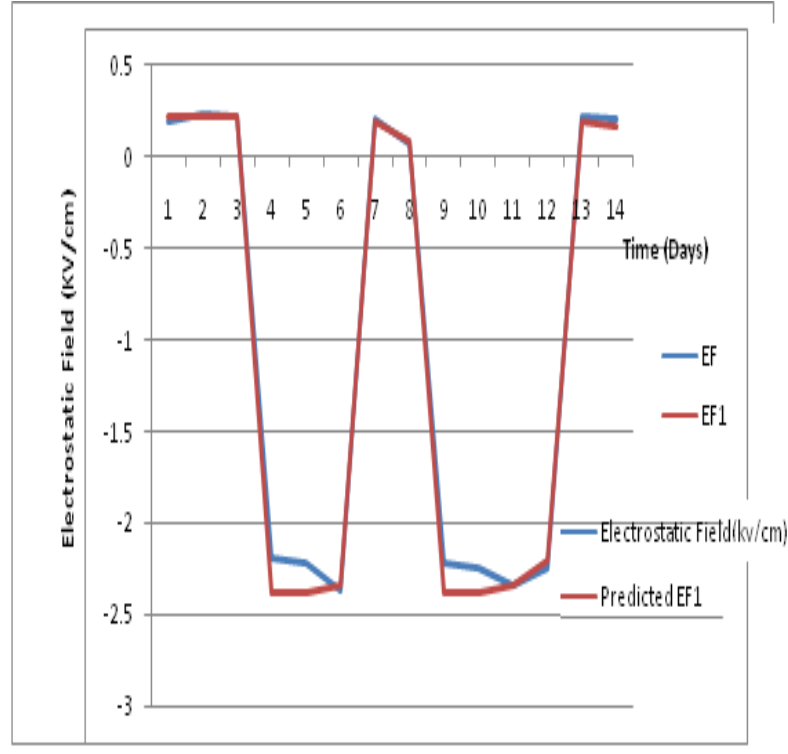

Figure 11: Model Plot of Electrostatic Field for Harmattan Season (Outside Scenario)

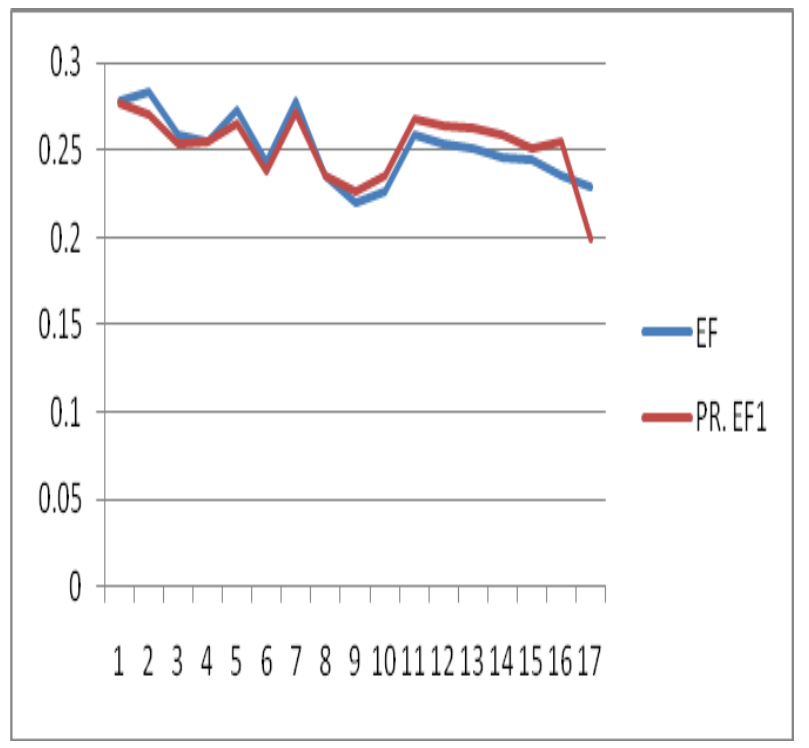

Figure 12: Model Plot of Hourly Electrostatic Field for Harmattan month (February)

From Figure $10-12$, the pattern of the graphs has an oscillating resemblance of Harris' plot and the maximum value occurred at the $10^{\text {th }}$ hour of the day as he experienced on the $4^{\text {th }}$ of February, 1967, [14]. The observer of a reversal in the polarity of the magnitude of several thousand by Harris was also acknowledged in the current research. However, from Fig.10, it was observed that the low relative humidity value was associated with the Harmattan period which influences the higher Electrostatic Field value, which could be seen from the data, higher relative humidity value is associated, which result in low values of electrostatic field, hence the prevalence of negative values of the fields. Although the oscillating pattern of electrostatic field obtained for the hourly measurement is similar to that obtained by Harris, but there was none exactly as his. The maximum field value obtained on the 4th of February were $0.25157 \mathrm{kV} / \mathrm{cm}$, $0.25579 \mathrm{kV} / \mathrm{cm}, 0.26579 \mathrm{kV} / \mathrm{cm}$ for 2008,2009 and 2010 respectively, as compared to $-0.0045 \mathrm{KV} / \mathrm{cm}$ obtained by Harris on $4^{\text {th }}$ February, 1967, which shows that there is a relative higher Electrostatic Field measurement in the current research than the former.

From Figure 10, 11 and 12, it could be observed that the peak of the electrostatic field strength was captured on the $9^{\text {th }}$ of February with the value of $0.4740 \mathrm{kV} / \mathrm{cm}$ in $2008,9^{\text {th }}$ of February with the value of $0.4856 \mathrm{kV} / \mathrm{cm}$ in 2009 and 0.5526 $\mathrm{kV} / \mathrm{cm}$ on the $10^{\text {th }}$ of February in 2010 while the while the minimum values was on the $4^{\text {th }}$ of Februaries of the periods. The weekly analysis established the non-linearity of the physical phenomenon-Harmattan. From the monthly graph during Harmattan, a typical for which is shown in figure 12, it could be deduced that electrostatic Field during Harmattan is more influenced by pressure and temperature. Therefore, the Neural Network Predict used to validate based on the Root Mean Square Error (RMSE) and the Pearson Correlation factor R. The R is a measure of how well the model follows the trends of the experimental data, while the RMSE is a function of the variation between the experimental data and the predicted one. The scenario was established for the Harmattan periods in the study area (Zaria), Nigeria.

Table 3 gives the Statistics summary from where $\mathrm{R}=$ Pearson correlation coefficient, is the correlation between the target output and the prediction. Net-R is the correlation between the target output and the neural net predicted output (internally transformed). Avg. Abs. is the average absolute error between the target output and the prediction. RMSE is the root mean square error between the target output and the prediction. $20 \%$ Accuracy refers to the closeness of the prediction to the expected output. 95\% Confidence Interval corresponds to the range [target value \pm confidence interval] within which the predicted output occurs given the specified degree of confidence. The result of the Neural Network predicts analysis yielded model plot of the Electrostatic Field during Harmattan (outside scenario) in Figure 11.

Table 1: HARMATTAN OUTSIDE DATA

\begin{tabular}{|c|c|c|c|c|c|c|c|}
\hline \multirow[t]{2}{*}{ Day } & \multirow{2}{*}{$\begin{array}{l}\text { Relative } \\
\text { Humidity } \\
\text { X3 (\%) }\end{array}$} & \multirow{2}{*}{$\begin{array}{l}\text { Temperature } \\
\text { X2 }\left({ }^{\circ} \mathrm{C}\right)\end{array}$} & \multirow{2}{*}{$\begin{array}{l}\text { Pressure } \\
\text { X3 } \\
(\mathbf{m m H g})\end{array}$} & \multirow{2}{*}{\begin{tabular}{l}
\multicolumn{2}{l}{ Experimental } \\
Value $\quad$ EF \\
$(\mathrm{kV} / \mathrm{cm})$
\end{tabular}} & $\begin{array}{l}\text { Predicted } \\
\text { EF1 }\end{array}$ & \multirow[t]{2}{*}{$\%$ dev } & \multirow[t]{2}{*}{ SE } \\
\hline & & & & & $(\mathrm{kV} / \mathrm{cm})$ & & \\
\hline $19 / 11 / 10$ & 57 & 29 & 706 & 0.192163 & 0.209432 & -8.98664 & 0.000298218 \\
\hline $22 / 11 / 10$ & 57 & 30 & 708 & 0.232091 & 0.209432 & 9.762981 & 0.00051343 \\
\hline $25 / 11 / 10$ & 60 & 30 & 708 & 0.225305 & 0.215605 & 4.305275 & $9.409 \mathrm{E}-05$ \\
\hline
\end{tabular}




\begin{tabular}{|c|c|c|c|c|c|c|c|}
\hline $28 / 11 / 10$ & 8 & 24 & 709 & -2.18877 & -2.37923 & -8.70169 & 0.036275012 \\
\hline $1 / 12 / 10$ & 57 & 29 & 706 & -2.2169 & -2.37923 & -7.32239 & 0.026351029 \\
\hline $4 / 12 / 10$ & 57 & 30 & 708 & -2.36212 & -2.34224 & 0.841617 & 0.000395214 \\
\hline $7 / 12 / 10$ & 60 & 30 & 709 & 0.20914 & 0.188939 & 9.65908 & 0.00040808 \\
\hline $10 / 12 / 10$ & 44 & 31 & 708 & 0.07384 & 0.074285 & -0.60265 & $1.98025 \mathrm{E}-07$ \\
\hline $13 / 12 / 10$ & 9 & 24 & 709 & -2.21962 & -2.37923 & -7.19087 & 0.025475352 \\
\hline $16 / 12 / 10$ & 57 & 30 & 708 & -2.24162 & -2.37923 & -6.13886 & 0.018936512 \\
\hline $19 / 12 / 10$ & 60 & 30 & 708 & -2.33685 & -2.34224 & -0.23065 & 2.90521E-05 \\
\hline $22 / 12 / 10$ & 44 & 30 & 708 & -2.24161 & -2.20784 & 1.506506 & 0.001140413 \\
\hline $25 / 12 / 10$ & 8 & 27 & 709 & 0.21823 & 0.188939 & 13.42208 & 0.000857963 \\
\hline $28 / 12 / 10$ & 9 & 24 & 709 & 0.18288 & 0.155989 & 14.70418 & 0.002198766 \\
\hline & & & & & & MSE & 0.008 \\
\hline & & & & & & RMSE & 0.089 \\
\hline & & & & & & $\mathbf{R}$ & 0.76 \\
\hline
\end{tabular}

Table 2: HARMATTAN INSIDE DATA

\begin{tabular}{|c|c|c|c|c|c|c|c|}
\hline \multirow[t]{2}{*}{ Day } & \multirow{2}{*}{$\begin{array}{l}\text { Relative } \\
\text { Humidity } \\
\text { X3 }(\%)\end{array}$} & \multirow[t]{2}{*}{$\begin{array}{l}\text { Temperature } \\
\text { X2 }\left({ }^{\circ} \mathrm{C}\right)\end{array}$} & \multirow[t]{2}{*}{$\begin{array}{l}\text { Pressure } \\
\text { X3 (mmHg) }\end{array}$} & \multirow[t]{2}{*}{\begin{tabular}{l}
\multicolumn{2}{l}{ Experimental } \\
Value $\quad$ EF \\
$(\mathrm{KV} / \mathrm{cm})$
\end{tabular}} & $\begin{array}{l}\text { Predicted } \\
\text { EF1 }\end{array}$ & \multirow[t]{2}{*}{$\% \mathrm{dev}$} & \multirow[t]{2}{*}{ SE } \\
\hline & & & & & $(\mathrm{kV} / \mathrm{cm})$ & & \\
\hline $19 / 11 / 10$ & 46 & 22 & 710 & 0.182053 & 0.191466 & -5.17047 & $8.86046 \mathrm{E}-05$ \\
\hline $22 / 11 / 10$ & 46 & 26 & 710 & 0.192235 & 0.191466 & 0.400031 & 5.91361E-07 \\
\hline $25 / 11 / 10$ & 47 & 27 & 712 & 0.216724 & 0.227398 & -4.92516 & 0.000113934 \\
\hline $28 / 11 / 10$ & 48 & 26 & 710 & 0.230393 & 0.241282 & -4.72627 & 0.00011857 \\
\hline $1 / 12 / 10$ & 89 & 36 & 714 & 0.076151 & 0.060147 & 9.076204 & 0.000256128 \\
\hline $4 / 12 / 10$ & 88 & 36.8 & 713.6 & 0.073714 & 0.076829 & -4.22579 & $9.70322 \mathrm{E}-06$ \\
\hline $7 / 12 / 10$ & 88 & 36.8 & 713.6 & 0.073714 & 0.076829 & -4.22579 & $9.70322 \mathrm{E}-06$ \\
\hline $10 / 12 / 10$ & 73 & 29 & 708 & -2.42755 & -2.37599 & 2.123952 & 0.002658434 \\
\hline $13 / 12 / 10$ & 60 & 30 & 708 & -2.28918 & -2.04293 & 10.75713 & 0.060639062 \\
\hline $16 / 12 / 10$ & 70 & 30.5 & 710 & -2.22014 & -2.40925 & -8.51793 & 0.035762592 \\
\hline $19 / 12 / 10$ & 73 & 29 & 708 & -2.42888 & -2.37599 & 2.177547 & 0.002797352 \\
\hline $22 / 12 / 10$ & 60 & 30 & 708 & -2.28903 & -2.04293 & 10.75128 & 0.06056521 \\
\hline $25 / 12 / 10$ & 70 & 30.5 & 710 & -2.22064 & -2.40925 & -8.4935 & 0.035573732 \\
\hline $28 / 12 / 10$ & 69 & 29 & 709 & -2.16417 & -2.39437 & -10.6369 & 0.05299204 \\
\hline $31 / 12 / 10$ & 73 & 29 & 708 & -2.42888 & -2.37599 & 2.177547 & 0.002797352 \\
\hline $03 / 01 / 11$ & 70 & 30.5 & 710 & -2.22064 & -2.40925 & -8.4935 & 0.035573732 \\
\hline & & & & & & MSE & 0.018 \\
\hline & & & & & & RMSE & 0.135 \\
\hline & & & & & & $\mathbf{R}$ & 0.77 \\
\hline
\end{tabular}


Table 3: Summary Statistics

\begin{tabular}{|c|c|c|c|c|c|c|c|c|}
\hline $\begin{array}{l}\text { Electro } \\
\text { static } \\
\text { Field } \\
(\mathrm{kv} / \mathrm{cm} \\
)\end{array}$ & $\mathbf{R}$ & $\begin{array}{l}\text { Net- } \\
\text { R }\end{array}$ & $\begin{array}{l}\text { Avg. } \\
\text { Abs. }\end{array}$ & $\begin{array}{l}\text { Max. } \\
\text { Abs. }\end{array}$ & RMS & $\begin{array}{l}\text { Accu } \\
\text { racy } \\
(\mathbf{2 0 \%} \\
)\end{array}$ & $\begin{array}{l}\text { Conf } \\
\text { Inter } \\
\text { val } \\
(95 \\
\%)\end{array}$ & $\begin{array}{l}\text { Reco } \\
\text { rds }\end{array}$ \\
\hline Train & $\begin{array}{l}0.684 \\
2\end{array}$ & $\begin{array}{l}- \\
0.70 \\
613\end{array}$ & $\begin{array}{l}0.495 \\
565\end{array}$ & $\begin{array}{l}2.031 \\
313\end{array}$ & $\begin{array}{l}0.785 \\
065\end{array}$ & $\begin{array}{l}0.690 \\
722\end{array}$ & $\begin{array}{l}1.549 \\
35\end{array}$ & 97 \\
\hline Test & $\begin{array}{l}0.779 \\
879\end{array}$ & $\begin{array}{l}- \\
0.78 \\
281\end{array}$ & $\begin{array}{l}0.373 \\
947\end{array}$ & $\begin{array}{l}2.001 \\
571\end{array}$ & $\begin{array}{l}0.645 \\
598\end{array}$ & $\begin{array}{l}0.790 \\
698\end{array}$ & $\begin{array}{l}1.298 \\
767\end{array}$ & 43 \\
\hline
\end{tabular}

\subsection{Observations from the Neural Network Statistical Summary}

From Table 3, the following observations were made with respect to Harmattan (inside) scenario: The Pearson R (train) $=0.68$ for the train data while the $\mathrm{R}$ (test) $=0.77$, for the test data. The closeness suggests that the model generalizes well and can make accurate prediction when it processes new data (data not obtained from the train or test data). Root mean Square (RMS) error was RMS (train) $=0.78$ and RMS (test) $=$ 0.64 for the train and test data respectively. The average absolute error Avg. Abs (train) $=0.50$ and Avg. Abs (test) $=0$. 37. From Table 6.6, the following observations were made with respect to Harmattan (outside) scenario: The Pearson $\mathrm{R}$ (train) $=0.66$ for the train data while the $\mathrm{R}$ (test) $=0.76$ for the test data. The closeness suggests that the model generalizes well and can make accurate prediction when it processes new data (data not obtained from the train or test data). Root mean Square (RMS) error was RMS (train) $=0.81$ and RMS (test) $=$ 0.68 for the train and test data respectively. The average absolute error Avg. Abs (train) $=0.50$ and Avg. Abs (test) $=$ 0.44 .

\subsection{Discussion of the Annual Analysis of the Electrostatic Field against the Co- Environmental Factors}

From the annual plot of Electrostatic field against coenvironmental factors, it could be deduced that Electrostatic Field during Harmattan is influenced by increase in temperature and pressure but decrease in relative humidity. High Electrostatic Field during this period is influenced by relatively high charge dust particles associated with the period.

\section{CONCLUSION}

The result of the analyses yielded good neural statistical values of Harmattan outside and inside Scenario of Root Mean Square (RMSE) of 0.09, Pearson R value of 0.76 and RMSE of $0.14, \mathrm{R}$ of 0.77 . However, these results show a reflections that all the $\mathrm{R}$ and the RMSE values are within the acceptable range of good model, hence it could be deduced that electrostatic fields distribution pattern during harmattan period in Zaria is dependent on the co-environmental factors i.e temperature, pressure, and humidity. With the insignificant value of the RMSE and the Pearson $\mathrm{R}$ value which are reflections of the closeness of the predicted and the experimental parameters, hence the Neural Network technique, could be relied upon to predict electrostatic field in Zaria, Nigeria.

\section{REFERENCES}

[1] S. Arisariwong, and S. Cahroenseang, "Reducing steady state error of a direct drive robot using Neuro-Fuzzy control", Proceedings of Second Asian Symposium on Industrial Automation and Robotics, Bangkok, Thailand, 2001.

[2] B. Nath, "Evolutionary and neural computation," bnath@csse.unimelb.edu.au, The University of Melbourne, Computer Science and Software Engineering, Semester 2, 2007, pp. 433-679.

[3] F. Qiu, "Neuro-Fuzzy based analysis of hyper spectral Imagery", Photogrammetric Engineering \& Remote Sensing, vol. 74, No. 10, pp. 1235-1247, October 2008.

[4] R. Fuller, "Neuro-Fuzzy methods for modeling and fault diagnosis," E"otv"os Lor'and university, Budapest Vacation School, Lisbon (Aug. 31 and September 1, 2002), pp. 1-22, 2001.

[5] D. Ihe, "Use of artificial neural network and fuzzy logic for Integrated Water Management: Review of Applications", Project Report, 2000, pp. 3-5.

[6] A. Abraham, and N.S. Philip, "Soft computing models for weather forecasting", 2001, http://meghnad.iucaa.ernet.in/ nspp/scs.pdf.

[7] A. Rotshtein, M. Posner, and H. Rakytyanska, "Prediction of the results of football games based on fuzzy model with genetic and neuro tuning", Eastern European Journal of Enterprise Technologies, 2003, pp. $10-15$.

[8] V. Edwards, "Artificial neural networks", 1998, http://aspac.web.unsw.edu.au/Media\%20Room/week4

[9] Purvis, M., Kaasabov, N., Benwell, G., Zhou, G., and Zhang, F., "Neuro-Fuzzy methods for environmental modeling", J. Sys. Res. Info. Sys., vol. 8, pp. $221-239$, 1999.

[10] M.B. Mu'azu, "Forecasting and modeling statistical phenomena using neurofuzzy logic: A case study of rainfall forecasting for Zaria", $\mathrm{PhD}$ Dissertation, Dept. Elect. Eng.,Ahmadu Bello Univ., Zaria, 2006.

[11] M.W. Gardner, and S.R. Dorling, “Artificial Neural Network (Multilayer Perceptron)- a review of applications in atmospheric sciences", Atmospheric Environment, vol. 32, 1998, pp. 2627-2636.

[12] I. Maqsood, R. K. Muhammad, and A. Abraham, Neurocomputing Based Canadian Weather Analysis. Computational Intelligence and Applications, Dynamic Publishers Inc., USA, 2002, pp.39-44.

[13] S. Chattopadhyay, Soft computing techniques in combating the complexity of the atmosphere - A review, 2008, http://arxiv.org/ftp/nlin/papers/0608/0608052.pdf

[14] O. Akinsanmi, B.G. Bajoga, and D.D. Dajab, "Comparative analysis of electric field measurement in Zaria”. Adv. Mater. Res., vol. 62-64, 2009, pp. 141-146. Neural Ware, 2003. 